\title{
Exploring Differential Interactions Between Rhizoctonia solani AG 2-t Isolates and Tulip Cultivars
}

J. H. M. Schneider and P. H. J. F. Van den Boogert, DLO-Research Institute for Plant Protection (IPO-DLO), P.O. Box 9060, 6700 GW Wageningen, the Netherlands; and J. C. Zadoks, Department of Phytopathology, Wageningen Agricultural University, P.O. Box 8025, 6700 EE, Wageningen, the Netherlands

\begin{abstract}
Schneider, J. H. M., Van den Boogert, P. H. J. F., and Zadoks, J. C. 1999. Exploring differential interactions between Rhizoctonia solani AG 2-t isolates and tulip cultivars. Plant Dis. 83:474481.

Experiments were conducted to explore differential interaction of Rhizoctonia solani AG 2-t isolates on tulip cultivars in soil artificially infested under different experimental conditions. Comparison of residual variances obtained by analysis of variance and by analysis of additive main effects and multiplicative interaction effects (AMMI) showed that open-air experiments should be used for interpretation of isolate by cultivar interaction. In open-air experiments, variability was lower than in greenhouse tests. In the biplot, derived after AMMI-analysis over isolates by years and by cultivars, isolates tended to occur in year clusters, indicating a differential effect of year on disease expression. Three isolates occurred in isolate clusters, thus accounting for a significant year by isolate by cultivar interaction. One cluster consisted of three isolates high in aggressiveness on all tested tulip cultivars, and another cluster consisted of three isolates low in aggressiveness. Greenhouse conditions and inoculum carrier significantly influenced quantitative differential interaction patterns. Isolates grown on oat kernels were more aggressive than those grown on autoclaved perlite particles soaked in liquid malt peptone. Differential interaction of AG 2-t isolates on tulip cultivars does occur, although it cannot yet be disentangled completely.
\end{abstract}

Additional keywords: partial resistance, Thanatephorus cucumeris

The plant pathogenic fungus Rhizoctonia solani Kühn (teleomorph: Thanatephorus cucumeris (A.B. Frank) Donk) affects agricultural and horticultural crops worldwide (27). T. cucumeris is regarded as a collective species (29) composed of genetically isolated groups (1), so-called anastomosis groups (AG) (3). To date, $12 \mathrm{AG}$ are recognized (27). AG are more homogenous in pathogenicity than the species at large (18). Within AG, isolates may vary in aggressiveness to specific cultivars. Cultivars may vary in susceptibility to specific isolates $(4,17,40)$.

Tulips are field-grown for salable bulbs, planting stock, and cut flowers. Most cut flowers are produced in the greenhouse under forced conditions, meaning that the flowering process is controlled by specific temperature treatments. Tulip cultivars are classified according to botanical origin, perianth morphology, and flowering period (5). Tulips belong to the family Liliaceae. The genus Tulipa is divided into the Leiostemones and Eriostemones. Most of

Corresponding author: J. H. M. Schneider E-mail: SCHNEIDER@IRS.NL

Accepted for publication 9 February 1999.

Publication no. D-1999-0318-01R

(C) 1999 The American Phytopathological Society today's cultivated tulips are placed in $T$. gesneriana, subgenus Leiostemones. Two garden tulips, T. turkestanica and T. tarda, belong to the section Biflores of the subgenus Eriostemones, and they do not intercross with $T$. gesneriana (34). Since the seventeenth century, breeders have been selecting Tulipa hybrids according to flower characteristics and forcing ability rather than disease resistance (20).

In the Netherlands, flower bulbs have been grown traditionally in the coastal area around Lisse, South-Holland province. More recently, tulips are being grown in the coastal area in the northern part of North-Holland province and in other parts of the Netherlands. Tulips are grown in short rotations such as Tulipa-NarcissusHyacinthus-Lilium (Iris) around Lisse and Tulipa-Narcissus-Crocus-Lilium in the new growing area of North-Holland. In the Zuyderzee Polders, tulips are grown in 6year rotations with Solanum tuberosum, Triticum aestivum, and Beta vulgaris.

In field-grown tulips, typical bare patches are caused by $R$. solani AG 2-t (26). Patches develop at low $\left(<9^{\circ} \mathrm{C}\right)$ temperatures $(10,24)$ when the sprouts are growing through the soil. Depending on the severity of sprout infection, development of daughter bulbs will be hampered, and at harvest, the bulb cluster may have decayed completely. Bulb rot, developing at higher $\left(>13^{\circ} \mathrm{C}\right)$ soil temperatures $(10,24)$ later in the growing season or in the greenhouse, may be caused by AG 2-t or other AG (10,24,26).

Rhizoctonia bare patch can be controlled by disinfecting bulbs and by full field application of fungicides such as tolclophosmethyl. For environmental reasons, chemical input has to be reduced, and alternative control strategies are being developed (9). One control strategy may be breeding for disease resistance. Differences in susceptibility of tulip cultivars to $R$. solani and differences in aggressiveness among fungal isolates have been demonstrated in greenhouse experiments $(10,26)$. Ranking of tulip cultivars for susceptibility to Rhizoctonia disease under field conditions is based on farmers' experiences (35), but tulip cultivars with resistance to $R$. solani are not yet known.

A procedure to screen tulip cultivars for susceptibility to AG 2-t isolates must take into account any variability for aggressiveness within a group of field isolates. Aggressiveness is the ability of a pathogen to attack a host, and therefore it is influenced by the host's susceptibility. Aggressiveness is quantifiable as the degree of attack (6) and is usually assessed on a range of host genotypes (2). Differential interaction occurs when the ranking of aggressiveness of isolates differs according to cultivars, with the possible implication of physiological specialization. Engelkes and Windels (11) reported statistically significant interactions between 17 AG 2-2 isolates and three sugar beet cultivars and three bean crops in field experiments. In sugar beet, but not in beans, there were significant differences among years, cultivars, and isolates. Schneider et al. (26) reported on statistically significant interactions between 11 AG 2-t isolates and three tulip cultivars under greenhouse conditions, explained by one specific isolate by cultivar combination.

The objective of this study was to explore interaction of AG 2-t isolates with tulip cultivars with respect to (i) differential interaction patterns, (ii) consistency of interaction patterns between years, (iii) consistency of interaction patterns between open-air and greenhouse experiments, and (iv) consistency of interaction patterns between inoculum sources.

\section{MATERIALS AND METHODS}

Fungal isolates and inoculum. During a field survey in $1991, R$. solani AG 2-t 
isolates were collected from commercial tulip fields in the Netherlands. Isolates were maintained on malt-peptone agar slants at $10^{\circ} \mathrm{C}$, as described previously (26). Nineteen AG 2-t isolates from different flower bulb hosts and geographic origins and two AG 2-1, three AG 2-2, and three AG 4 isolates were used in this study (Table 1). Inoculum was prepared by growing the isolates on autoclaved oat kernels $(10,26)$ or autoclaved perlite particles soaked in liquid malt peptone (PMP) (30) for 2 to 3 weeks at $20^{\circ} \mathrm{C}$ in the dark. In general, the isolates produced more and larger sclerotia on oat kernels than on PMP.

Tulip cultivars. Nineteen tulip cultivars (Table 2) were selected according to the 10 tulip groups within $T$. gesneriana, botanical species and hybrids (5), and their production areas. Tulip bulbs were obtained from commercial breeders and stored according to breeders' practices at $17^{\circ} \mathrm{C}$ in the dark until planted in the field. Prior to use in greenhouse experiments, bulbs were pretreated at $2^{\circ} \mathrm{C}$ in the dark during 10 weeks.

Open-air experiments. Experiment 1 was conducted during the 1993-94 growing season using 19 AG 2-t, two AG 2-1, three AG 2-2, and three AG 4 isolates (Table 1) and 18 tulip cultivars (Table 2 ) in miniplots $(40 \times 80 \mathrm{~cm})$. To prevent cross-contamination, miniplots were separated by polyethylene sheets $40 \mathrm{~cm}$ deep in the soil. Two bulbs of each of 18 tulip cultivars were planted side by side $8 \mathrm{~cm}$ deep in our standard 2:1 sand:potting soil mixture (26). At planting, two oat kernels infested with $R$. solani were placed near the neck of each bulb. The experimental design was a balanced completely randomized split plot with six blocks. Whole-plots were isolates and cultivars were subplots. Isolate wholeplots were spaced $30 \mathrm{~cm}$ apart. At flowering, about mid-April, disease severity was rated on a 0 to 8 scale as described below. At harvest, the fresh weight of the bulb clusters (mother bulb and daughter bulbs) was determined. At planting, emergence, and flowering, plants were fertilized with a standard NPK mixture (Sporumix PG [Windmill Holland, Vlaardingen, the Netherlands]) according to farmers' practices.

Experiment 2, conducted during the 1994-95 growing season, repeated part of experiment 1 using a limited set of AG 2-t isolates and cultivars. A selection of isolates and cultivars was made using preliminary results of a cluster analysis according to Corsten and Denis (7). One bulb was planted in a plastic pot $(11 \times 11 \times 13$ $\mathrm{cm}$ ) filled with our standard soil mixture as described above. Soil was infested by placing two $R$. solani-infected oat kernels overgrown with the isolate in a corner of each pot. A split-plot experiment with a randomized complete block design with six replicates was used. Whole-plots were isolates and subplots were cultivars. All
Table 1. Anastomosis groups (AG), codes, and origins of $R$. solani isolates ${ }^{\mathrm{a}}$ used in this study

\begin{tabular}{llll}
\hline AG & IPO code & Host $^{\mathbf{b}}$ & Location \\
\hline $2-1$ & $21 R 51$ & Oil-seed rape & Netherlands \\
$2-1$ & $21 R 61$ & Lily & Netherlands \\
$2-\mathrm{t}$ & $2 \mathrm{tR} 002$ & Red Riding Hood & Noordwijkerhout (S) \\
$2-\mathrm{t}$ & $2 \mathrm{tR} 101$ & Varinas & Breezand (N) \\
$2-\mathrm{t}$ & $2 \mathrm{tR} 105$ & Menton & Breezand (N) \\
$2-\mathrm{t}$ & $2 \mathrm{tR} 107$ & Estella Rijnveld & Julianadorp (N) \\
$2-\mathrm{t}$ & $2 \mathrm{tR} 109$ & Giant Parrot & Noordwijkerhout (S) \\
$2-\mathrm{t}$ & $2 \mathrm{tR} 111$ & Inzell & Noordwijkerhout $(\mathrm{S})$ \\
$2-\mathrm{t}$ & $2 \mathrm{tR} 114$ & Iris 'White Excelsior' & Heemskerk (M) \\
$2-\mathrm{t}$ & $2 \mathrm{tR} 118$ & Leen van der Mark & Castricum (M) \\
$2-\mathrm{t}$ & $2 \mathrm{tR} 123$ & Judith Leyster & St. Pancras (N) \\
$2-\mathrm{t}$ & $2 \mathrm{tR} 124$ & Judith Leyster & St. Pancras (N) \\
$2-\mathrm{t}$ & $2 \mathrm{tR} 125$ & Gander & Breezand (N) \\
$2-\mathrm{t}$ & $2 \mathrm{tR} 128$ & Pink Supreme & Anna Paulowna (N) \\
$2-\mathrm{t}$ & $2 \mathrm{tR} 130$ & Polo & Lisse (S) \\
$2-\mathrm{t}$ & $2 \mathrm{tR} 132$ & Isis & Lisse (S) \\
$2-\mathrm{t}$ & $2 \mathrm{tR} 133$ & Heart's Delight & De Zilk (S) \\
$2-\mathrm{t}$ & $2 \mathrm{tR} 135$ & Red Riding Hood & De Zilk (S) \\
$2-\mathrm{t}$ & $2 \mathrm{tR} 139$ & Red Riding Hood & Den Helder (N) \\
$2-\mathrm{t}$ & $2 \mathrm{tR} 142$ & Red Riding Hood & Lisse (S) \\
$2-\mathrm{t}$ & $2 \mathrm{tR} 144$ & Fashion & Lisse (S) \\
$2-2 \mathrm{IIIB}$ & $22 \mathrm{R} 01$ & Mat rush & Japan \\
$2-2 \mathrm{IV}$ & $22 R 02$ & Sugar beet & Japan \\
$2-2$ & $22 R 11$ & Sugar beet & Netherlands \\
4 & $4 \mathrm{R} 11$ & Bean & Netherlands \\
4 & $4 R 22$ & Iris & Netherlands \\
4 & $4 R 51$ & Lettuce & Netherlands \\
\hline & & &
\end{tabular}

a Details on isolates are described elsewhere $(25,26)$.

${ }^{b}$ AG 2-t isolates were isolated from tulip cultivars, except for 2tR114, which was isolated from iris.

${ }^{\mathrm{c}}$ Locations in the Netherlands: S, traditional bulb growing area near Lisse, South-Holland province; $\mathrm{N}$, "new" bulb area in the northern part of North-Holland province; M, area between S and N.

Table 2. Taxonomical position ${ }^{\mathrm{a}}$ of tulip cultivars and their susceptibility ${ }^{\mathrm{b}}$ to Rhizoctonia disease used in our experiments and the cultivar of isolation in Table 1

\begin{tabular}{lcccc}
\hline Taxonomy & Abbreviation & Group & Susceptibility & Flowering \\
\hline Section: Tulipa & & & & \\
Tulipa gesneriana & & & & \\
Aladdin & Ala & LT & 2 & Late \\
Angélique & Ang & DLT & 4 & Late \\
Apeldoorn & Apd & DTH & 2 & Mid \\
Christmas Marvel & ChM & EVT & 3 & Early \\
Estella Rijnveld & EsR & PT & 5 & Late \\
Gander & Gan & ELT & 3 & Late \\
Inzell & Inz & TT & 4 & Mid \\
Isis & Isi & FT & $\ldots$ & Late \\
Judith Leyster & JuL & ELT & 1 & Late \\
Leen van der Mark & LvdM & TT & 2 & Mid \\
Menton & Men & ELT & 2 & Late \\
Monte Carlo & MoC & DVT & 2 & Early \\
Pink Supreme & PiS & ELT & 3 & Late \\
Spring Green & SpG & VFT & $\ldots$ & Late \\
Varinas & Var & TT & $\ldots$ & Mid \\
Section: Eichleres & & & & \\
T. greigii & & & & \\
Giant Parrot & GiP & GRE & 3 & Mid \\
Red Riding Hood & RRH & GRE & $\ldots$ & \\
T. kaufmanniana & & & & \\
Fashion & Fas & KAU & $\ldots$ & Early \\
Hearts Delight & HeD & KAU & 3 & \\
T. fosteriana & & & & \\
Polo & Pol & FOS & $\ldots$ & Early \\
Subgenus: Eriostemones & & & & \\
Section: Biflores & Tar & OSP & $\ldots$ & \\
T. tarda & Tur & OSP & $\ldots$ & \\
T. turkestanica & & & \\
\hline EVT s & & & & \\
\hline
\end{tabular}

${ }^{\mathrm{a}} \mathrm{EVT}=$ single early; DVT $=$ double early; ELT $=$ single late; $\mathrm{TT}=$ triumph; DTH $=$ Darwin-hybrid; LT = lily-flowered; FT = fringed; VFT = Viridiflora; PT = parrot; DLT = double late; Tulipa species and their hybrids: $\mathrm{KAU}=$ Kaufmanniana; $\mathrm{GRE}=$ Greigii; FOS $=$ Fosteriana; OSP $=$ other species and their varieties and hybrids. Classification of tulips according to the Classified list (5).

${ }^{\mathrm{b}}$ Susceptibility to Rhizoctonia disease on a scale from $1=$ not susceptible to $5=$ very susceptible (35). 
other experimental procedures were the same as in experiment 1 . In a parallel experiment 3 , the same cultivars and isolates were used, but the inoculum was prepared by culturing the fungus on PMP.

Greenhouse experiments. Tulip bulbs were pretreated at $2^{\circ} \mathrm{C}$ before use in greenhouse experiments 4 and 5. Tulip cultivars were grown in controlled walk-in climate chambers for 6 weeks at $9^{\circ} \mathrm{C}$ (day and night). One bulb was planted per plastic pot $(7 \times 7 \times 9 \mathrm{~cm})$ filled with our standard soil mixture. Soil was infested with $R$. solani isolates by placing two oat kernels (experiment 4) or two PMP particles (experiment 5) on the neck of each bulb. Pots were watered by hand. Disease severity was rated on a 0 to 8 scale (see disease assessment). A split-plot experiment with a randomized complete block design with four replicates was used. Whole-plots were isolates and subplots were cultivars. For all experiments, noninfested soil was used as a control.

Disease assessment. For all experiments, infection of aboveground stem parts and leaves was rated on a 0 to 8 scale (with $\%$ infected leaf area): $0=$ no symptoms; 1 $=0.1 \%$, a few $(\leq 5)$ small $(\leq 0.5 \mathrm{~mm})$ lesions on the leaves; $2=0.1$ to $1 \%$, several lesions $(>5)$ or 1 to 2 larger $(>0.5 \mathrm{~mm})$ lesions; $3=1$ to $5 \%,>2$ larger $(>0.5 \mathrm{~mm})$ lesions and leaves distorted (gapped or frayed); $4=5$ to $25 \%$, distortion of leaves up to $25 \%$, 1 leaf severely infected, or a strong growth reduction up to $25 \% ; 5=25$ to $50 \%$, moderate to severe infection of the leaves; $6=50$ to $75 \%$, up to $75 \%$ of the sprout severely infected; $7=75$ to $95 \%$, severely infected sprout and no leaves developed; $8=95$ to $100 \%$, sprout severely infected or not emerged.
Statistical analysis. Analysis of variance (ANOVA) was used to test statistical interaction between AG 2-t isolates and tulip cultivars. Full interaction models with an interaction parameter for every cell in the two-way isolate by cultivar table have huge numbers of interaction parameters in case of many isolates or cultivars. Parsimonious models accounting for most of the relevant interaction might be obtained using additive main effects and multiplicative interaction effects (AMMI) models $(13,32,33)$. Multiplicative models for interaction bridge the gap between the main effects model and the full interaction model and are used to explore isolate by cultivar interaction patterns. AMMI is an explorative technique by which the research question can be expressed directly in terms of interaction patterns to be derived in biplots $(16,19)$. A biplot is a graphical representation in which isolate and cultivars are displayed simultaneously. The interaction is described in terms of differential sensitivities of the isolates to the most discriminating environmental variables that can be constructed. These hypothetical environmental variables (AMMI-axes) and the isolate sensitivities are estimated from the table itself. In general, the first axis accounts for the largest amount of interaction, followed by a second axis, orthogonal to the first, and so on.

The interpretation of the biplot is simple. Isolates with vector endpoints far removed from the origin contribute relatively more to the interaction than isolates with vector endpoints close to the origin. Pairs of isolates for which the endpoints of the vectors are far apart show considerable interaction. Isolates for which the directions of the vectors almost coincide have similar patterns of interaction. When the directions are opposite, the interaction patterns of the corresponding isolates show negative correlation. If two isolate vectors are orthogonal, the interaction patterns are unrelated. Pairs of isolates and pairs of cultivars, which show considerable interaction, can be easily identified from a biplot by looking for pairs of isolate vectors and pairs of cultivar vectors for which the lengths of the difference vectors are large and for which the difference vectors are almost parallel. As a rule, conclusions from biplots are most reliable for isolates and cultivars with their vector ends far apart (high nonadditivity). Isolates and cultivars close to the origin contribute little to the interaction and cannot be discriminated from bias and were excluded from statistical analysis after preliminary exploration.

Prior to AMMI analysis, disease severity data (DS) were logit transformed as $\operatorname{logit}(\mathrm{DS})=\log ([\mathrm{DS}+(1 / 2 n)] /[8-(\mathrm{DS}$ $+1 / 2 n)])$, with $n$ as the number of replicates. All statistics were done in Genstat release 5.3 (14). Genstat programs for AMMI analysis and visualization in biplots were kindly provided by F. A. van Eeuwijk (WAU) and P. F. G. Vereijken (CPRO-DLO), respectively.

\section{RESULTS}

Interactions in open-air experiments. In experiment 1 , during the 1993-94 growing season, all $19 R$. solani AG-2-t isolates affected leaves and stems of all 18 tulip genotypes. At flowering, average disease severity varied from 1.9 (several lesions) to 8.0 (sprout severely infected) (Table 3). Isolates 2tR002, 2tR132, and 2tR142 were highly aggressive on all tulip cultivars tested. Isolates $2 \mathrm{tR} 105,2 \mathrm{tR} 114$,

Table 3. Experiment 1, 1994, average disease severitya of tulip cultivars grown in microplots infested with isolates of Rhizoctonia solani AG 2-t and oat kernels as inoculum carrier

\begin{tabular}{|c|c|c|c|c|c|c|c|c|c|c|c|c|c|c|c|c|c|c|c|c|}
\hline Cultivar & Ala $^{\mathbf{b}}$ & Inz & JuL & Apd & Tar & Men & Gan & SpG & Var & Pol & ChM & LvdM & MoC & Ang & RRH & PiS & HeD & Tur & Avg & Var \\
\hline \multicolumn{21}{|l|}{ Isolate } \\
\hline $2 \mathrm{tR} 002$ & 7.1 & 7.3 & 7.0 & 7.2 & 7.3 & 7.0 & 7.4 & 7.7 & 7.7 & 7.5 & 7.6 & 7.7 & 7.8 & 7.7 & 7.7 & 7.7 & 7.7 & 7.7 & 7.5 & 0.1 \\
\hline $2 \mathrm{tR} 142$ & 5.3 & 5.8 & 6.6 & 6.2 & 6.3 & 6.7 & 6.9 & 7.0 & 6.6 & 6.5 & 7.0 & 6.8 & 7.5 & 7.4 & 6.3 & 7.5 & 7.4 & 7.3 & 6.8 & 0.4 \\
\hline $2 \mathrm{tR} 132$ & 6.6 & 7.2 & 4.8 & 6.1 & 5.7 & 6.2 & 5.9 & 6.6 & 7.3 & 4.4 & 7.2 & 6.2 & 6.8 & 6.9 & 7.2 & 7.3 & 6.0 & 6.8 & 6.4 & 0.7 \\
\hline $2 \mathrm{tR} 101$ & 3.8 & 4.2 & 4.3 & 5.7 & 5.6 & 6.7 & 6.4 & 4.8 & 7.6 & 6.3 & 6.9 & 8.0 & 7.6 & 7.3 & 7.2 & 8.0 & 8.0 & 8.0 & 6.5 & 2.0 \\
\hline $2 \mathrm{tR} 111$ & 3.2 & 3.9 & 4.9 & 6.8 & 6.3 & 6.0 & 6.0 & 6.6 & 5.7 & 6.3 & 6.8 & 7.4 & 6.5 & 6.6 & 7.1 & 7.5 & 7.5 & 7.6 & 6.3 & 1.5 \\
\hline 2tR109 & 1.9 & 5.0 & 4.8 & 4.9 & 5.9 & 5.5 & 6.1 & 5.3 & 5.6 & 6.8 & 6.8 & 7.6 & 6.5 & 6.8 & 7.3 & 7.1 & 7.6 & 7.8 & 6.1 & 2.0 \\
\hline $2 \mathrm{tR} 130$ & 3.4 & 5.8 & 3.9 & 5.1 & 3.7 & 5.9 & 6.0 & 5.9 & 6.9 & 5.8 & 5.0 & 6.9 & 7.3 & 7.6 & 7.0 & 7.1 & 7.7 & 7.3 & 6.0 & 1.8 \\
\hline $2 \mathrm{tR} 125$ & 2.8 & 4.3 & 5.5 & 5.5 & 4.9 & 4.6 & 6.3 & 5.0 & 6.0 & 4.9 & 7.1 & 6.6 & 6.4 & 7.2 & 6.7 & 7.0 & 7.5 & 7.6 & 5.9 & 1.7 \\
\hline $2 \mathrm{tR} 128$ & 3.8 & 5.9 & 5.1 & 4.4 & 3.9 & 5.1 & 6.1 & 4.8 & 6.3 & 6.2 & 6.1 & 5.9 & 7.7 & 7.1 & 6.6 & 6.6 & 7.3 & 7.3 & 5.9 & 1.4 \\
\hline $2 \mathrm{tR} 123$ & 4.8 & 3.5 & 3.5 & 3.9 & 3.5 & 5.5 & 5.5 & 6.5 & 5.3 & 6.5 & 6.8 & 7.5 & 7.2 & 6.4 & 7.4 & 6.9 & 6.8 & 7.0 & 5.8 & 2.0 \\
\hline $2 \mathrm{tR} 133$ & 2.1 & 3.2 & 4.2 & 5.1 & 4.2 & 5.4 & 5.7 & 6.7 & 6.2 & 4.9 & 6.2 & 6.1 & 6.6 & 6.2 & 6.3 & 7.3 & 7.7 & 7.7 & 5.7 & 2.3 \\
\hline 2tR107 & 3.2 & 4.7 & 4.7 & 4.0 & 4.5 & 4.6 & 5.2 & 6.1 & 5.3 & 5.8 & 6.7 & 5.3 & 6.3 & 5.8 & 6.7 & 7.9 & 7.6 & 7.6 & 5.6 & 1.7 \\
\hline $2 \mathrm{tR} 124$ & 3.3 & 2.1 & 2.3 & 4.6 & 5.8 & 3.7 & 4.3 & 5.3 & 4.3 & 5.3 & 6.3 & 5.6 & 6.0 & 7.4 & 7.7 & 7.2 & 7.8 & 7.6 & 5.4 & 3.3 \\
\hline 2tR139 & 2.4 & 4.3 & 3.4 & 4.7 & 4.6 & 3.7 & 5.8 & 4.9 & 4.5 & 6.8 & 5.3 & 5.8 & 5.2 & 6.8 & 6.9 & 7.4 & 7.7 & 7.5 & 5.4 & 2.3 \\
\hline $2 \mathrm{tR} 135$ & 2.6 & 3.1 & 3.8 & 4.2 & 2.9 & 4.6 & 3.2 & 6.0 & 5.9 & 2.9 & 5.4 & 6.7 & 5.2 & 6.3 & 6.5 & 6.7 & 7.6 & 7.6 & 5.0 & 2.9 \\
\hline $2 \mathrm{tR} 118$ & 3.8 & 1.9 & 4.5 & 2.3 & 3.5 & 3.4 & 5.5 & 4.3 & 3.8 & 5.1 & 6.1 & 4.6 & 6.1 & 6.6 & 6.3 & 7.2 & 7.8 & 7.6 & 5.0 & 3.1 \\
\hline $2 \mathrm{tR} 114$ & 1.9 & 2.8 & 2.9 & 5.0 & 5.0 & 4.7 & 3.3 & 5.0 & 4.0 & 6.3 & 6.2 & 3.9 & 4.0 & 5.3 & 6.0 & 7.2 & 7.6 & 7.5 & 4.9 & 2.8 \\
\hline $2 \mathrm{tR} 144$ & 2.0 & 2.1 & 3.9 & 2.5 & 6.3 & 6.1 & 2.2 & 2.8 & 3.7 & 5.0 & 5.0 & 5.0 & 4.5 & 6.1 & 6.7 & 6.8 & 7.0 & 7.8 & 4.7 & 3.6 \\
\hline $2 \mathrm{tR} 105$ & 2.6 & 2.0 & 2.3 & 3.9 & 4.1 & 3.1 & 3.0 & 4.2 & 3.5 & 3.7 & 5.3 & 5.4 & 6.2 & 6.7 & 4.2 & 7.8 & 7.7 & 7.8 & 4.6 & 3.7 \\
\hline Avg & 3.5 & 4.2 & 4.3 & 4.8 & 4.9 & 5.2 & 5.3 & 5.5 & 5.6 & 5.6 & 6.3 & 6.3 & 6.4 & 6.7 & 6.7 & 7.2 & 7.5 & 7.5 & 5.8 & \\
\hline Var & 2.3 & 2.8 & 1.5 & 1.6 & 1.5 & 1.4 & 2.0 & 1.4 & 1.8 & 1.3 & 0.6 & 1.3 & 1.2 & 0.4 & 0.6 & 0.2 & 0.2 & 0.1 & & \\
\hline
\end{tabular}

a Disease severity from 0 (no symptoms) to 8 (sprout completely rotted) assessed at flowering in an open-air experiment.

b Abbreviations for cultivars are in Table 2. 
and 2tR144 were highly variable, and on average, low in aggressiveness toward the tested cultivars (Table 3 ). In a preliminary statistical analysis of interactions, isolates 2tR107, 2tR111, and 2tR125 and cultivars Angelique, Christmas Marvel, and Red Riding Hood were close to the origin on four AMMI-axes, indicating additivity rather than interaction, and thus they were omitted from further analysis.

Analysis of variance using an AMMI-5 model on logit transformed disease severity data revealed that four AMMI-axes seemed necessary for an adequate description of the interactions. The first four axes accounted for $38,18,10$, and $9 \%$ of the interaction sum of squares (SS), respectively (Table 4). The mean square error (MSE) estimated from the AMMI-4 analysis was $(8.51+24.58) /(20+90)=0.30$, which was remarkably close to 0.27 , the residual error derived from ANOVA (data not shown).

Considerable interaction occurred between isolates 2tR101-2tR132, because their vector ends are far apart on a logit scale (Fig. 1). The same holds for isolate pairs 2tR101-2tR114, 2tR101-2tR144, 2tR132-2tR114, and 2tR105-2tR132 and for cultivar pairs of Inzell-Hearts Delight, Inzell-T. tarda, Inzell-Leen van der Mark, Hearts Delight-Varinas, Hearts Delight $-T$. tarda, and Hearts Delight-Leen van der Mark. The interaction pattern, ignoring size, was comparable for isolate groups 2tR002-2tR132-2tR142, 2tR105-2tR1242tR118, and 2tR123-2tR128-2tR130, as indicated by almost coinciding vector directions. Isolate $2 \mathrm{tR} 132$ was separated from 2tR002 and 2tR142 along the third axis (Figure not shown). Since four AMMI-axes seemed necessary for a sound description of the interaction sum of squares, we consider the biplot as a whole rather than explaining the interactions in terms of individual axes. To the left of Figure 1 are the highly aggressive (HA) isolates 2tR002, 2tR142, and 2tR132 and to the bottom is HA isolate 2tR101. Isolates low in aggressiveness (LA), 2tR114, 2tR144, and 2tR105, are grouped to the upper right of Figure 1. Isolate 2tR101 is separated from 2tR105, 2tR124, and 2tR144 along the fourth axis (Figure not shown). Cultivars are grouped according to susceptibility to AG 2-t isolates. The highly susceptible cultivars $(H S) T$. turkestanica, Hearts Delight, and Pink Supreme were grouped to the right, whereas the susceptible cultivars Leen van der Mark and Varinas were grouped to the bottom left of Figure 1. The least susceptible $(L S)$ cultivar, Inzell, was positioned to the left in Figure 1. Axis 2 showed a weak grouping of the cultivars according to botanical origin and flowering period. T. tarda is a botanical species, flowering in early April, whereas Leen van der Mark and Varinas are Triumph tulips flower in April-May (Table 2). Cultivar pairs Leen van der Mark-Varinas and Gander-Monte Carlo are separated along the fourth axis when plotted against the second axis (Figure not shown). Axis 4 separated the isolates according to their geographical origin in the Netherlands (Figure not shown; percent variance explained by the interaction SS was 9\% [Table 4]). Isolates 2tR002, 2tR114, $2 \mathrm{tR} 132$, and $2 \mathrm{tR} 144$ were isolated from fields located around Lisse, whereas isolates 2tR101, 2tR105, 2tR118, and 2tR124 were isolated from more recently established fields in the north of North-Holland.

The four-dimensional structure underlying the biplot (Fig. 1) made tetradeanalysis difficult. Two tetrades were found. DS for isolate 2tR101 for cultivars Aladdin and Polo was 3.8 and 6.3, respectively, whereas DS for isolate 2tR132 was 6.6 and 4.4 for these cultivars (Table 3). Another tetrade revealed interaction between 2tR109, 2tR132, Aladdin, and Polo (Table 3). Inspection of the biplot using AMMIaxis 1 and AMMI-axis 3 revealed interaction between isolate pairs 2tR105-2tR002, 2tR105-2tR109, 2tR105-2tR132, 2tR1092tR132, and 2tR132-2tR144 and cultivar pairs Polo-Aladdin, Inzell-Hearts Delight, and Polo-Hearts Delight (Figure not shown).

At flowering in experiment 1 , isolates 21R51 and 21R61, and three isolates of AG-2-2 and three isolates of AG-4 had not caused distinct lesions on the leaves. At harvest, however, all of these isolates had caused small lesions $(\leq 0.5 \mathrm{~mm})$ on the stem base near the soil surface. In general, AG 2-1, AG 2-2, and AG 4 isolates reduced the fresh weight of bulb clusters at harvest less than did AG-2-t isolates (24).
Since only a few isolates per AG were used, their interactions were not explored statistically.

Consistency of the interaction pattern in open-air experiments. In experiment 2 , during the 1994-95 growing season, part of the experiment 1 was repeated using nine AG 2-t isolates and 11 tulip genotypes. At flowering, all AG 2-t isolates had infected the tested tulip cultivars. Disease severity varied from 2.1 to 8.0 (Table 5). Analysis of variance on logit transformed DS of isolates and cultivars common to experiments 1 and 2 revealed a significant year by isolate by cultivar interaction $(P<$ 0.001; ANOVA data not shown). MSEs derived from ANOVA for isolates and cultivars common to 1994 and 1995 were 0.25 and 0.42 , respectively. In 1994, the percent residual subplot variance (\%RsV) was 22 , and in 1995 it was 28. Both MSE and $\% \mathrm{RsV}$ indicated that experimental conditions were better in 1994 than in 1995, but they gave comparable results. Year by isolate by cultivar interaction was further explored by AMMI. Four axes explained $35,19,14$, and $13 \%$ of the interaction sum of squares. The first two AMMI-axes were used to display interaction in a biplot. Isolates 2tR105, 2tR118, and 2tR144 tended to occur in year clusters (Fig. 2). For example, isolate 2tR144 reacted differently on Aladdin and T. tarda, with a DS of 2.0 and 6.3 in 1994 and 5.2 and 4.6 in 1995 (Tables 3 and 5). Isolates 2tR002, 2tR130, and 2tR135 tended to occur in an isolate cluster, indicating no year effect (Fig. 2). Isolates 2tR130-95 and 2tR114-95 were separated from isolates 2tR002-94, 2tR130-94, and 2tR142-94 along the second and third AMMI-axis (Figure not shown). Isolates $2 \mathrm{tR} 002$ and 2tR144 were more aggressive on some cultivars, e.g., Ala, Inz, and Tar, in 1994 than in 1995 (Tables 3 and 5). On average, isolate 2tR002 was more aggressive in 1994 than in 1995, with a mean DS of 7.4 and 5.6, respectively. On average, cultivar Monte Carlo reacted differently between years, with a mean DS of 6.1 in 1994 and a mean DS of 3.7 in 1995.

Comparison of interactions in openair and greenhouse experiments. After 6 weeks of incubation in the greenhouse at $9^{\circ} \mathrm{C}$, there were disease symptoms on

Table 4. Experiment 1, 1994, analysis of variance for an AMMI-5 model fitted to the logit transformed mean disease severity of tulip genotypes caused by R. solani AG 2-t isolates

\begin{tabular}{|c|c|c|c|c|c|c|c|c|c|}
\hline Source & df & & $\begin{array}{l}\text { Sum of } \\
\text { squares }\end{array}$ & $(\% \mathrm{SS})$ & $\begin{array}{l}\text { Mean } \\
\text { square }\end{array}$ & & $\begin{array}{l}\text { Variance } \\
\text { ratio }\end{array}$ & & $F$ probability \\
\hline Isolate & 15 & & 106.52 & & 7.10 & & 26.00 & & $<<0.001$ \\
\hline Genotype & 14 & & 242.96 & & 17.35 & & 63.54 & & $<<0.001$ \\
\hline AMMI-axis 1 & & 28 & 50.12 & $(38)$ & & 1.79 & & 6.55 & $<<0.001$ \\
\hline AMMI-axis 2 & & 26 & 23.49 & (18) & & 0.90 & & 3.31 & $<<0.001$ \\
\hline AMMI-axis 3 & & 24 & 12.72 & (10) & & 0.53 & & 1.94 & 0.013 \\
\hline AMMI-axis 4 & & 22 & 11.99 & (9) & & 0.55 & & 1.99 & 0.013 \\
\hline AMMI-axis 5 & & 20 & 8.51 & (7) & & 0.43 & & 1.56 & 0.081 \\
\hline Residual & & 90 & 24.58 & (19) & & 0.27 & & & \\
\hline Total & 239 & & 480.89 & & 2.01 & & & & \\
\hline
\end{tabular}


leaves and stems of all 10 tulip genotypes inoculated with the oat kernels of eight $R$. solani AG-2-t isolates (experiment 4). Disease severity varied from 2.0 to 7.0 (Table 6). Percentage RsV obtained by ANOVA was $23 \%$. The experimental condition (open-air versus greenhouse) interaction was explored by AMMI. The first four axes explained $30,26,15$, and $11 \%$ of the interaction sum of squares. The first two axes of a biplot were used for inspection of the interactions. In the open-air experiment, isolates tended to occur in two clusters, whereas in the greenhouse the same isolates occurred in one cluster (Fig. 3 ), which indicates that the interaction pattern differed according to the experimental conditions.

Differential interaction by inoculum carrier. In experiment 3, designed as ex- periment 2, PMP was used as inoculum carrier. On average, disease symptoms on the 10 tulip genotypes caused by the eight tested AG-2-t isolates were significantly less (ANOVA; $P<0.001$ ) with PMP than with oat kernels. The residual variances were 0.42 and 0.56 for oat kernels and PMP, respectively. Average disease severity varied from 0.0 to 7.5 (Table 6). The first four axes explained $31,19,16$, and

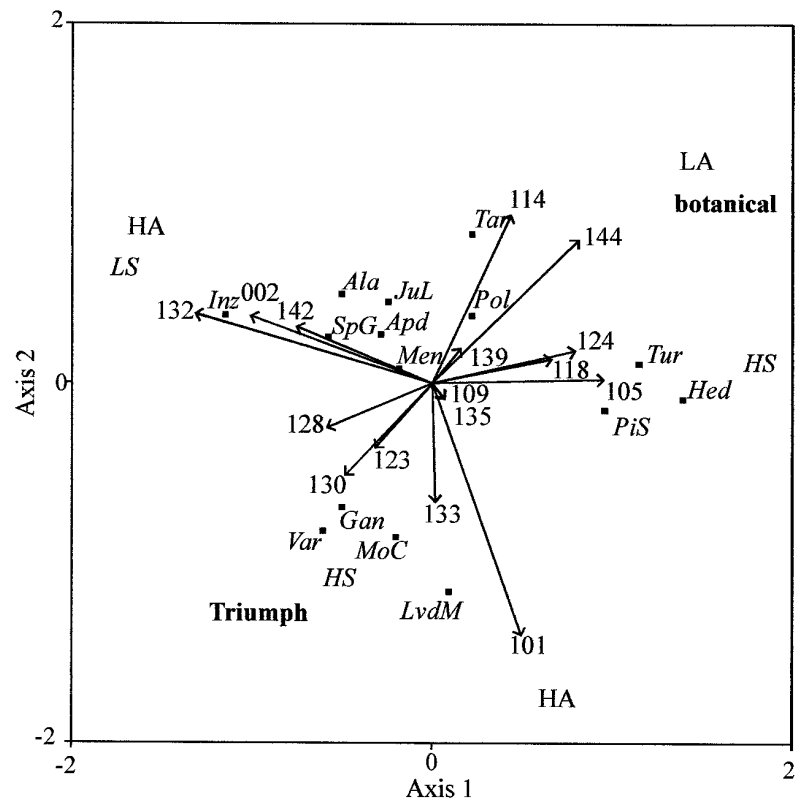

Fig. 1. Biplot of the Rhizoctonia solani AG 2-t isolate by tulip cultivar interaction under open-air conditions on the logit transformed disease severity data of Table 3 (experiment 1). AG 2-t isolates are represented by arrows, cultivars by squares. Abbreviations of cultivar names are in Table 2. The most outlying isolates contribute considerably to the interaction. Coinciding arrows indicate comparable interaction patterns. LA and HA: low and high aggressiveness; $L S$ and $H S$ : low and high susceptibility.

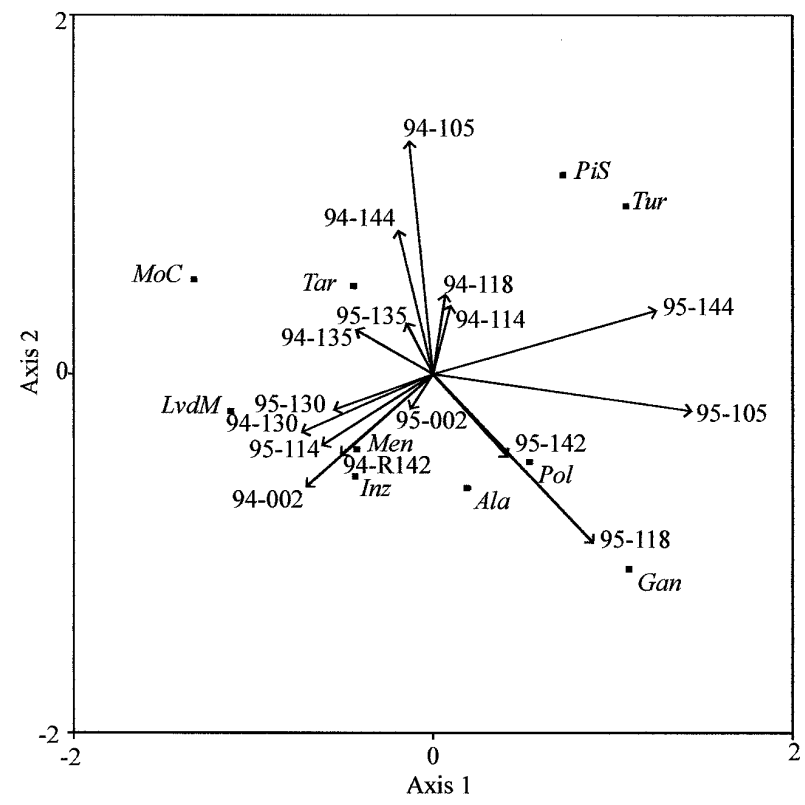

Fig. 2. Biplot of the Rhizoctonia solani AG 2-t isolate by tulip cultivar interaction under open-air conditions in 2 years on logit transformed disease class data of isolates and cultivars common in experiment 1 (Table 3) and experiment 2 (Table 6). AG 2-t isolates by year combinations are represented by arrows, cultivars by squares. Abbreviations of cultivars are in Table 2. The most outlying isolate by year combinations contribute considerably to the interaction. Coinciding arrows indicate comparable interaction patterns.

Table 5. Experiments 2 and 3, 1995, disease severity ${ }^{\mathrm{a}}$ of tulip cultivars grown in pots infested with isolates of Rhizoctonia solani AG 2-t $\mathrm{t}^{\mathrm{b}}$

\begin{tabular}{|c|c|c|c|c|c|c|c|c|c|c|c|c|c|}
\hline & Cultivar & $\operatorname{Tar}^{\mathrm{c}}$ & Inz & MoC & Ala & Gan & Men & LvdM & Pol & PiS & Fas & Tur & AVG \\
\hline Inoculum & Isolate & & & & & & & & & & & & \\
\hline \multirow[t]{10}{*}{ Oat kernels } & $2 \mathrm{tR} 142$ & 4.7 & 4.1 & 4.0 & 3.6 & 6.3 & 6.3 & 7.6 & 7.4 & 6.3 & 7.7 & 8.0 & 6.0 \\
\hline & $2 \mathrm{tR} 125$ & 3.0 & 3.0 & 4.8 & 4.8 & 6.3 & 5.8 & 7.5 & 7.5 & 7.7 & 7.8 & 7.5 & 6.0 \\
\hline & 2tR002 & 4.2 & 4.2 & 3.8 & 6.5 & 3.5 & 5.5 & 7.5 & 6.7 & 7.1 & 6.3 & 7.3 & 5.7 \\
\hline & 2tR144 & 5.2 & 4.0 & 3.2 & 4.6 & 5.4 & 3.5 & 3.6 & 7.4 & 8.0 & 7.6 & 8.0 & 5.5 \\
\hline & $2 \mathrm{tR} 105$ & 2.8 & 3.7 & 2.0 & 3.9 & 7.2 & 5.2 & 2.9 & 6.2 & 7.5 & 6.7 & 8.0 & 5.1 \\
\hline & 2tR114 & 4.3 & 3.2 & 4.5 & 3.3 & 3.4 & 5.5 & 6.0 & 4.8 & 5.0 & 7.3 & 7.2 & 5.0 \\
\hline & $2 \mathrm{tR} 135$ & 2.8 & 3.4 & 4.5 & 3.8 & 4.2 & 3.6 & 5.7 & 3.2 & 7.8 & 7.6 & 6.8 & 4.9 \\
\hline & $2 \mathrm{tR} 130$ & 2.7 & 4.8 & 4.3 & 3.3 & 2.8 & 5.6 & 5.7 & 5.0 & 7.5 & 5.8 & 5.3 & 4.8 \\
\hline & $2 \mathrm{tR} 118$ & 2.3 & 2.4 & 2.1 & 5.1 & 5.8 & 3.8 & 3.0 & 5.7 & 5.7 & 6.5 & 6.5 & 4.4 \\
\hline & Avg & 3.6 & 3.6 & 3.7 & 4.3 & 5.0 & 5.0 & 5.5 & 6.0 & 6.9 & 7.0 & 7.2 & 5.3 \\
\hline \multirow[t]{10}{*}{ PMP } & $2 \mathrm{tR} 144$ & 1.3 & 3.9 & 4.5 & 7.4 & 6.0 & 4.2 & 4.8 & 2.8 & 6.0 & 5.7 & 7.4 & 4.9 \\
\hline & 2tR002 & 2.3 & 2.3 & 4.2 & 3.7 & 3.8 & 2.2 & 6.2 & 2.2 & 7.5 & 5.2 & 7.4 & 4.3 \\
\hline & $2 \mathrm{tR} 125$ & 2.2 & 3.3 & 3.0 & 7.0 & 5.5 & 4.7 & 3.3 & 3.0 & 3.1 & 4.1 & 7.6 & 4.3 \\
\hline & 2tR142 & 2.0 & 4.4 & 3.1 & 1.7 & 1.2 & 4.7 & 3.4 & 6.5 & 5.4 & 3.9 & 7.1 & 3.9 \\
\hline & $2 \mathrm{tR} 105$ & 1.2 & 2.6 & 2.7 & 5.8 & 2.0 & 7.7 & 2.8 & 2.4 & 5.3 & 2.8 & 7.0 & 3.8 \\
\hline & 2tR114 & 0.9 & 1.8 & 2.0 & 1.4 & 4.8 & 3.2 & 3.0 & 0.6 & 7.1 & 2.6 & 4.8 & 2.9 \\
\hline & 2tR118 & 0.3 & 1.0 & 2.7 & 1.9 & 2.2 & 1.8 & 2.6 & 1.0 & 1.4 & 3.3 & 2.8 & 1.9 \\
\hline & $2 \mathrm{tR} 130$ & 0.0 & 1.6 & 0.4 & 2.4 & 1.3 & 0.3 & 5.9 & 1.5 & 1.2 & 0.8 & 0.0 & 1.4 \\
\hline & $2 \mathrm{tR} 135$ & 0.3 & 1.0 & 1.7 & 0.0 & 1.0 & 0.8 & 1.2 & 0.5 & 0.0 & 1.6 & 0.3 & 0.8 \\
\hline & Avg & 1.2 & 2.5 & 2.7 & 3.5 & 3.1 & 3.3 & 3.7 & 2.3 & 4.1 & 3.3 & 4.9 & 3.1 \\
\hline
\end{tabular}

${ }^{a}$ Disease severity from 0 (no symptoms) to 8 (sprout completely rotted) assessed at flowering in open-air experiments.

${ }^{\mathrm{b}}$ Isolates were provided with oat kernels (experiment 2) or liquid malt peptone (PMP) (experiment 3 ) as inoculum carrier.

c Abbreviations for cultivars are in Table 2. 
$12 \%$ of the interaction sum of squares. Isolates tended to cluster in inoculum clusters (Fig. 4), indicating that the interaction pattern depended on the type of inoculum. To the upper right of Figure 4, isolates grown on PMP prevail, whereas to the lower left, isolates grown on oat kernels dominate. Isolate 2tR142 grown on PMP seems to occur between isolate clusters grown on oat kernels, but it was separated from O-2tR114 and O-2tR142 along the third axis (Figure not shown).

In experiment $5, \% \mathrm{RsV}$ obtained by ANOVA was $40 \%$ with PMP in the greenhouse, considerably more than with oat kernels $(\% \mathrm{RsV}=24 \%)$ used as inoculum. Therefore, experiment 5 was not further analyzed.

\section{DISCUSSION}

A strategy for sustainable control of Rhizoctonia bare patch in field-grown tulips, based on disease resistance management, requires insight into the variability of field isolates. The rationale for performing our experiments was to assess whether a previously reported statistical interaction between $A G$ 2- $t$ isolates and tulip cultivars in greenhouse experiments (26) indicated a "real" isolate by cultivar interaction, with the implication of physiological races within AG 2-t, or an interaction induced by environmental factors.

Comparison of MSE derived by ANOVA and AMMI for the different experiments shows that conclusions should be based mainly on the results of the openair experiments 1 and 2. Experiment 2 was performed in pots and gave more variable results. Perhaps the variation was caused by differences in root growth, microclimatic conditions, and soil infestation. In experiment 1 , two oat kernels were placed on the neck of each bulb, so that soil as a growth medium hardly played a role. In experiment 2, two oat kernels were placed in one corner of the pot, implying that the pathogen had to grow actively through the soil before infection of the bulb could take place. Differences in competitive saprophytic growth between isolates may partially explain variability in experiment 2 .

Differential interaction. The statistical significance of four AMMI-axes indicated complex interactions. Quantitative differential interactions for DS were found. Differential interaction may suggest a gradual evolution toward physiological specialization (42). The genetic background of differential interaction is unknown. The observed interaction patterns for foliar disease severity were not found again in the bulb weight data (24). The observed discrepancy between the two disease parameters may indicate that sprout and bulb infection are different pathogenic processes. Sprouts grow through the soil from early January to March, whereas tulips develop daughter bulbs between flowering in April and harvest in June.

The interaction between experiments 1 and 2 was mainly due to a differential effect of years on the disease severity for tulip cultivars. Isolates tended to occur in year clusters. Van Eeuwijk (32) suggested horizontal resistance (31) for this phenomenon when analyzing the interaction between four Fusarium isolates and 17 wheat cultivars. Parlevliet and Zadoks (23) showed that horizontal resistance can be explained by polygenic resistance, with individual genes operating on a gene for gene basis. Isolates 2tR130 and 2tR135 tended to occur in isolate clusters, thus indicating the same interaction pattern for these isolates in both years. Pathogenicity in $R$. solani has been shown to be poly- genic (12). Genetic studies in our $R$. solani AG 2-t-tulip pathosystem are lacking. We therefore prefer to use the term quantitative differential interaction, indicating an environmentally influenced partial resistance. Zadoks and Van Leur (42) suggested that "training" might explain a small interaction phenomenon. Thus far, no breeding of tulip cultivars resistant to $R$. solani has been done, and consequently no training of isolates took place. It is worthwhile to select isolates 2tR105, 2tR118, 2tR144, 2tR002, 2tR130, and 2tR135, accounting for quantitative differential interaction, for further testing under commercial breeders' practices and for genetic studies.

Tetrade analysis yielded only some five highly interactive tetrads. In view of the many tetrades distinguishable, significance could be due to chance effects only ( $\beta$ error). The tetrade interaction $T$. tardaGander $\times 2$ tR139-2tR144 was found twice, for DS and for bulb weight (24), so that only this differential interaction was confirmed.

Variability among $R$. solani AG 2-t isolates. Highly aggressive isolates originating from the South showed the same interaction pattern and showed a negatively correlated interaction pattern with isolates originating from the North. Our tested AG 2-t isolates form a homogeneous subgroup according to hyphal fusion frequency (26), pectic zymography (25), and ITS rDNA sequence analysis (O. Salazar, J. H. M. Schneider, M. C. Julián, J. Keijer, and V. Rubio, unpublished). Minor differences in ITS rDNA restriction patterns and base pair sequences, however, were found (O. Salazar, J. H. M. Schneider, M. C. Julián, J. Keijer, and V. Rubio, unpublished; 25). Pectic zymograms seem to be related to pathogenicity of isolates $(25,28)$, and the production of polygalacturonase may be

Table 6. Experiments 4 and 5, 1995, average disease severity a of tulip cultivars grown in the greenhouse in pots infested with isolates of Rhizoctonia solani AG 2-t $\mathrm{t}^{\mathrm{b}}$

\begin{tabular}{|c|c|c|c|c|c|c|c|c|c|c|c|c|}
\hline & Cultivar & LvdMc & Gan & Ala & Inz & Pol & Men & Fas & RRH & PiS & Tur & AVG \\
\hline Inoculum & Isolate & & & & & & & & & & & \\
\hline \multirow{9}{*}{ Oat } & $2 \mathrm{tR} 114$ & 2.6 & 3.6 & 6.2 & 5.5 & 4.3 & 6.4 & 6.8 & 5.0 & 7.5 & 7.3 & 5.5 \\
\hline & $2 \mathrm{tR} 105$ & 4.8 & 4.8 & 3.4 & 3.4 & 4.8 & 5.3 & 7.0 & 6.3 & 7.3 & 7.0 & 5.4 \\
\hline & $2 \mathrm{tR} 135$ & 3.3 & 3.8 & 5.3 & 4.5 & 4.5 & 3.3 & 7.0 & 7.0 & 6.8 & 7.0 & 5.2 \\
\hline & $2 \mathrm{tR} 118$ & 3.5 & 4.5 & 3.7 & 4.0 & 3.8 & 4.4 & 4.7 & 6.3 & 6.0 & 7.0 & 4.8 \\
\hline & $2 \mathrm{tR} 142$ & 3.3 & 3.5 & 4.8 & 3.3 & 4.3 & 4.1 & 7.4 & 4.0 & 6.3 & 7.3 & 4.8 \\
\hline & $2 \mathrm{tR} 130$ & 2.8 & 3.0 & 2.0 & 4.0 & 4.6 & 3.4 & 3.1 & 6.8 & 6.9 & 7.3 & 4.4 \\
\hline & $2 \mathrm{tR} 144$ & 2.0 & 3.0 & 4.0 & 3.8 & 3.5 & 3.1 & 2.8 & 7.0 & 6.3 & 7.0 & 4.2 \\
\hline & $2 \mathrm{tR} 002$ & 2.5 & 2.6 & 2.4 & 3.8 & 3.5 & 3.5 & 5.5 & 5.7 & 4.4 & 7.0 & 4.1 \\
\hline & Avg & 3.1 & 3.6 & 4.0 & 4.0 & 4.1 & 4.2 & 5.5 & 6.0 & 6.4 & 7.1 & 4.8 \\
\hline \multirow[t]{9}{*}{ PMP } & $2 \mathrm{tR} 105$ & 2.0 & 2.0 & 2.9 & 2.0 & 2.5 & 3.0 & 4.0 & 4.7 & 2.0 & 4.9 & 3.0 \\
\hline & $2 \mathrm{tR} 002$ & 2.0 & 1.8 & 2.0 & 2.3 & 2.5 & 2.3 & 2.5 & 2.8 & 1.9 & 6.0 & 2.6 \\
\hline & $2 \mathrm{tR} 118$ & 2.3 & 2.5 & 1.4 & 2.3 & 2.5 & 2.5 & 3.0 & 1.8 & 2.3 & 4.3 & 2.5 \\
\hline & $2 \mathrm{tR} 142$ & 2.0 & 2.0 & 2.0 & 1.8 & 3.0 & 1.7 & 3.3 & 3.3 & 2.5 & 3.4 & 2.5 \\
\hline & $2 \mathrm{tR} 144$ & 1.8 & 2.3 & 0.5 & 2.5 & 1.8 & 3.0 & 2.8 & 2.3 & 3.0 & 4.0 & 2.4 \\
\hline & $2 \mathrm{tR} 130$ & 2.3 & 2.8 & 0.6 & 2.0 & 2.5 & 2.3 & 2.8 & 1.3 & 2.8 & 4.0 & 2.3 \\
\hline & $2 \mathrm{tR} 114$ & 2.0 & 1.0 & 1.5 & 1.8 & 2.8 & 2.0 & 3.3 & 2.5 & 3.3 & 2.3 & 2.2 \\
\hline & $2 \mathrm{tR} 135$ & 1.8 & 1.3 & 1.5 & 2.0 & 2.0 & 2.8 & 2.5 & 2.5 & 3.4 & 0.9 & 2.0 \\
\hline & Avg & 2.0 & 1.9 & 1.6 & 2.1 & 2.4 & 2.4 & 3.0 & 2.6 & 2.7 & 3.7 & 2.4 \\
\hline
\end{tabular}

${ }^{\text {a }}$ Disease severity of 0 (no symptoms) to 8 (sprout completely rotted) assessed after 6 weeks of growth in the greenhouse at $9^{\circ} \mathrm{C}$.

${ }^{\mathrm{b}}$ Isolates were provided with oat kernels (experiment 4) or liquid malt peptone (PMP) (experiment 5) as inoculum carrier.

c Abbreviations for cultivars are in Table 2. 
related to virulence (15). Yang et al. (39) reported that the expression of pectic enzymes by field isolates involved multiple genes and that the variation in pectic enzyme patterns among homokaryotic strains could be explained by two types of nuclei. We could find no clear relation between the profile of our pectic enzyme pattern and the aggressiveness of AG 2-t isolates (J. H. M. Schneider, unpublished). Field isolates of $R$. solani are multinucleate and heterokaryotic, and therefore the observed quantitative differential interaction was not unexpected.

Thus far, the teleomorph of $R$. solani AG 2-t has not been found in the field. Doornik (10) demonstrated that mycelium of $R$. solani in infected tulip bulbs survived during storage and thus could act as a source of infection in the next planting. Variability in pathogenicity may have its origin in the introduction of subpopulations of $R$. solani into the new bulb growing areas by means of planting material. Natural populations spread over a large area hardly ever are genetically homogeneous (8). DNA fingerprinting techniques allow the investigation of genetic variability of $R$. solani isolates in relation to pathogenicity and population structure. Once these relations have been unraveled, we may be able to develop DNA-markers for detection of specific pathogenic isolates and the study of the origin of genetic heterogeneity.

Partial resistance. In flower bulbs, breeding for disease resistance has been neglected for a long time, but for environmental reasons it becomes more important.
Our data using a limited set of tulip cultivars demonstrated partial resistance in some cultivars. Thus, breeding for resistance holds promise but will require many years. Problems in tulip breeding are the incompatibility in interspecific crosses (36), the low propagation rate, and the poor documentation on cultivar genealogies (20). Biotechnology to overcome these problems is still in its infancy, but first results are encouraging (38). Partial resistance may have its merits. Partial resistance is characterized by a reduced rate of epidemic development in spite of a susceptible infection type (22). When the level of partial resistance is high enough, partially resistant cultivars may reduce the amount of inoculum (41). Partial resistance often is polygenically determined and sensitive to environmental condition (41). Selecting tulip cultivars for partial resistance may be difficult and could, perhaps, be done best under semicommercial growing conditions, as was suggested for the barley-leaf rust pathosystem (22). The most virulent isolates in our study may be used to develop rapid screening procedures and to test for resistance under commercial breeders' practices.

Exogenous nutrients. An understanding of inoculum sources that influence disease expression of plant pathogens may contribute to a more sustainable disease management. The isolate by cultivar interaction pattern was influenced by the inoculum carrier in both open-air and greenhouse experiments. Only isolate 2tR142 did not interact with inoculum source. To our knowledge, the present report is the first to describe differential interaction due to inoculum source for $R$. solani. Isolates of $R$. solani were more aggressive with oat kernels as the inoculum carrier than with PMP. These results are in line with previous observations (J. H. M. Schneider, unpublished) and reports of McCoy and Kraft (21) and Weinhold et al. (37). The latter showed that damping-off in cotton seedlings increased with an increasing asparagine concentration in the inoculum disks. They also demonstrated that aggressiveness of $R$. solani was influenced by nitrogen and carbon in the soil solution and by nutrients provided by host exudates. The former reported that virulence of inoculum depended on the inoculum source and that virulence was directly affected by sucrose and peptone concentrations. Furthermore, they observed that the overall rating of pea lines was independent of the inoculum source. We found that the overall rating of cultivar susceptibility varied with inoculum carrier. Both inoculum carriers in our experiments were undefined media, but the observed influence on disease expression signals the need to conduct studies on inoculum sources in the field and energy flow in the $R$. solani-tulip pathosystem.

In summary, our results showed that disease expression in open-air experiments was quantitative and that interactions between AG 2-t isolates and tulip cultivars did occur but were influenced by environment. There are no reasons yet to assume physiological specialization of AG 2-t isolates to tulip cultivars. We thus recom-

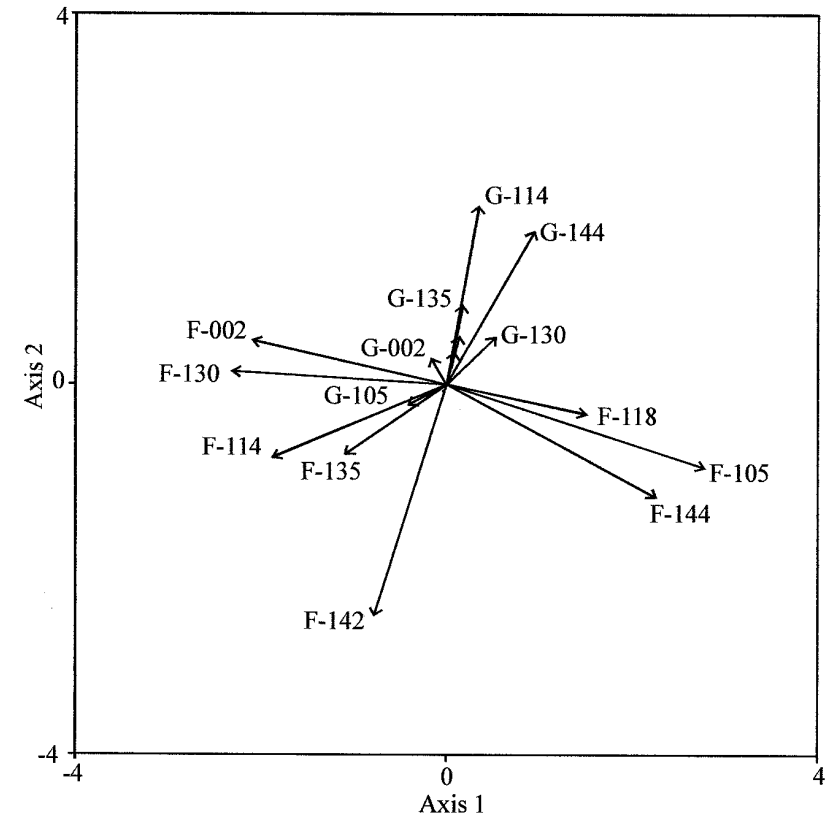

Fig. 3. Biplot of the Rhizoctonia solani AG 2-t isolate by tulip cultivar interaction on logit transformed disease class data of isolates and cultivars used in open-air $(\mathrm{F})$ and greenhouse $(\mathrm{G})$ experiments. Oat kernels were used as inoculum carrier. AG 2-t isolates by experimental condition ( $\mathrm{F}$ or $\mathrm{G}$ ) are represented by arrows. The most outlying arrowheads contribute considerably to the interaction. Coinciding arrows indicate similar interaction patterns.

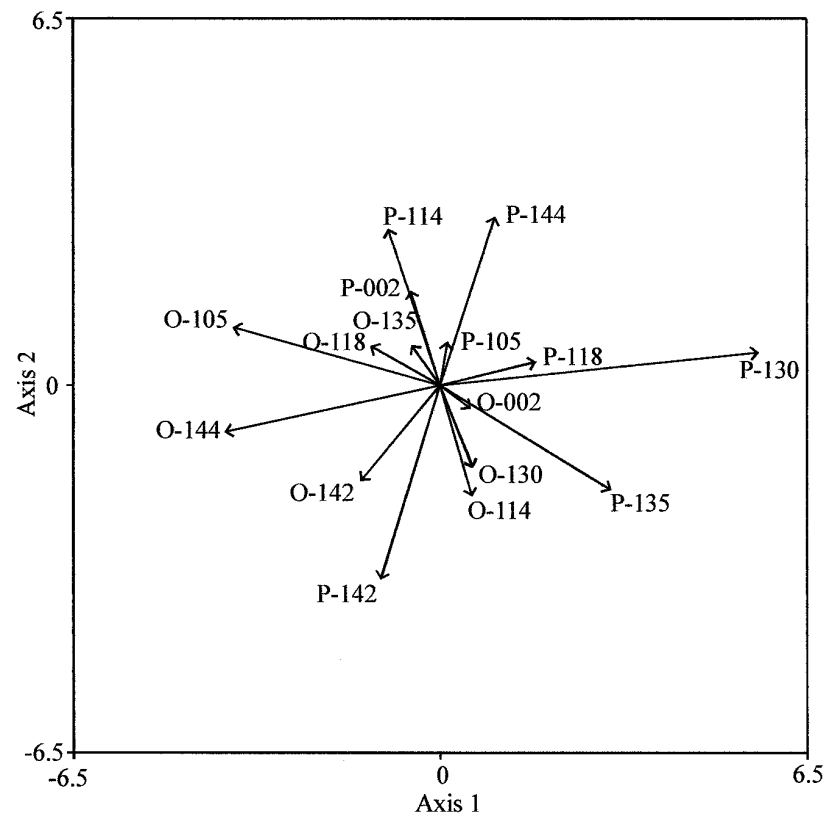

Fig. 4. Biplot of the Rhizoctonia solani AG 2-t isolate by tulip cultivar interaction under open-air conditions in experiment 2 using oat kernels (O) and perlite-malt-peptone (P) as inoculum carriers on logit transformed disease class data of Table 6. AG 2-t isolates by inoculum are represented by arrows. The most outlying arrowheads contribute considerably to the interaction. Coinciding arrows indicate similar interaction patterns. 
mend testing partially resistant cultivars in at least two areas in concordance with a thorough characterization of the indigenous pathogenic $R$. solani population. An integrated use of partial resistance and biological control or light pesticide applications may provide an adequate control of Rhizoctonia disease in field-grown tulips. The abundance of bulb rot-causing isolates of AG 2-1, AG 2-2, and AG 4 in commercial fields requires further study.

\section{ACKNOWLEDGMENTS}

J. H. M. Schneider was financially supported by the Urgency Program for Research on Diseases and Breeding of Flower Bulbs. We thank M. T. Schilder for technical assistance, A. W. Doornik (Bulb Research Centre, LBO) for technical information on tulip breeding and for providing plant materials, and P. F. G. Vereijken (DLO-Centre for Plant Breeding and Reproduction Research) and F. A. van Eeuwijk (Department of Mathematics, Wageningen Agricultural University) for providing Genstat programs for AMMI-analysis and statistical advice for analyzing the data. We thank N. J. Fokkema (IPO-DLO) for critical reading of the manuscript.

\section{LITERATURE CITED}

1. Anderson, N. A. 1982. The genetics and pathology of Rhizoctonia solani. Annu. Rev. Phytopathol. 20:329-347.

2. Bos, L., and Parlevliet, J. E. 1995. Concepts and terminology on plant/pest relationships: Towards consensus in Plant Pathology and crop protection. Annu. Rev. Phytopathol. 33:69-102.

3. Carling, D. E. 1996. Grouping in Rhizoctonia solani by hyphal anastomosis reaction. Pages 37-43 in: Rhizoctonia species: Taxonomy, Molecular Biology, Ecology, Pathology and Control. B. Sneh, S. Jabaji-Hare, S. M. Neate, and G. Dijst, eds. Kluwer, Dordrecht, Netherlands.

4. Carling, D. E., and Leiner, R. H. 1990. Virulence of isolates of Rhizoctonia solani AG-3 collected from potato plant organs and soil. Plant Dis. 74:901-903.

5. Classified List and International Register of Tulip Names. 1987. Koninklijke Algemeene Vereeniging voor Bloembollencultuur (KAVB), Hillegom.

6. Commissie voor de terminologie van de Koninklijke Nederlandse Planteziektenkundige Vereniging. 1997. Lijst van gewasbeschermingskundige termen. Gewasbescherming 28. Suppl. nr. 1.

7. Corsten, L. C. A., and Denis, J. B. 1990. Structuring interaction in two tables by clustering. Biometrics 46:207-215.

8. Crow, J. F. 1986. Basic Concepts in Population, Quantitative, and Evolutionary Genetics. Freeman, New York.

9. Dijst, G., and Schneider, J. H. M. 1996. Flower bulb diseases incited by Rhizoctonia species. Pages 279-288 in: Rhizoctonia species: Taxonomy, Molecular Biology, Ecology, Pathology and Control. B. Sneh, S. JabajiHare, S. M. Neate, and G. Dijst, eds. Kluwer,
Dordrecht, Netherlands.

10. Doornik, A. W. 1981. Temperature dependence of the pathogenicity of several isolates of Rhizoctonia solani in some bulb crops as an intrinsic property of the isolate. Neth. J. Plant Pathol. 87:139-147.

11. Engelkes, C. A., and Windels, C. E. 1996. Susceptibility of sugar beet and beans to Rhizoctonia solani AG-2-2 IIIB and AG-2-2 IV. Plant Dis. 80:1413-1417.

12. Garza-Chapa, R., and Anderson, N. A. 1966. Behavior of single basidiospore isolates and heterokaryons of Rhizoctonia solani from flax. Phytopathology 56:1260-1268.

13. Gauch, H. G. 1988. Model selection and validation for yield trials with interaction. Biometrics 44:705-715.

14. Genstat 5 Committee. 1994. Genstat 5 Release 3 Reference Manual. Clarendon, Oxford.

15. Geypens, M. 1978. Enzymatic production and virulence of Rhizoctonia isolates. Ann. Phytopathol. 3:355-363.

16. Gower, J. C. and Hand, D. J., 1996. Biplots. Chapman and Hall, London.

17. Kaminski, D. A., and Verma, P. R. 1985. Cultural characteristics, virulence, and in vitro temperature effect on mycelial growth of Rhizoctonia isolates from rapeseed. Can. J. Plant Pathol. 7:256-261.

18. Keijer, J., Houterman, P. M., Dullemans, A. M., and Korsman, M. G. 1997. In vitro analysis of host plant specificity in Rhizoctonia solani. Plant Pathol. 46:659-669.

19. Kempton, R. A. 1984. The use of biplots in interpreting variety by environment interactions. J. Agric. Sci. Cambridge 103:123-135.

20. Le Nard, M., and De Hertogh, A. A. 1993. Tulipa. Pages 617-682 in: The Physiology of Flower Bulbs. A. A. De Hertogh and M. Le Nard, eds. Elsevier, Amsterdam.

21. McCoy, R. J., and Kraft, J. M. 1984. Comparison of techniques and inoculum sources in evaluating peas (Pisum sativum) for resistance to stem rot caused by Rhizoctonia solani. Plant Dis. 68:53-55.

22. Parlevliet, J. E., and Van Ommeren, A. 1975. Partial resistance to leaf rust, Puccinia hordei. II. Relationship between field trials, micro plot tests and latent period. Euphytica 24:293-303.

23. Parlevliet, J. E., and Zadoks, J. C. 1977. The integrated concept of disease resistance: A new view including horizontal and vertical resistance in plants. Euphytica 26:5-21.

24. Schneider, J. H. M. 1998. Rhizoctonia disease of tulip: Characterization and dynamics of the pathogens. Ph.D. thesis. Wageningen Agricultural University, Wageningen, Netherlands.

25. Schneider, J. H. M., Salazar, O., Rubio, V., and Keijer, J. 1997. Identification of Rhizoctonia solani isolates associated with fieldgrown tulips using ITS rDNA polymorphism and pectic zymograms. Eur. J. Plant Pathol. 103:607-622

26. Schneider, J. H. M., Schilder, M. T., and Dijst, G. 1997. Characterization of Rhizoctonia solani AG 2 isolates causing bare patch in fieldgrown tulips in the Netherlands. Eur. J. Plant Pathol. 103:265-269.

27. Sneh, B., Jabaji-Hare, S., Neate, S. M., and Dijst, G., eds. 1996. Rhizoctonia Species:
Taxonomy, Molecular Biology, Ecology, Pathology and Control. Kluwer, Dordrecht, Netherlands.

28. Sweetingham, M. W., Cruickshank, R. H., and Wong, D. H. 1986. Pectic zymograms and taxonomy and pathogenicity of the Ceratobasidiaceae. Trans. Br. Mycol. Soc. 86:305311.

29. Talbot, P. H. B. 1970. Taxonomy and nomenclature of the perfect state. Pages 20-31 in: Rhizoctonia solani: Biology and Pathology. J. R. Parmeter, ed. University of California, Berkeley.

30. Van den Boogert, P. H. J. F., and Jager, G. 1984. Biological control of Rhizoctonia solani on potatoes by antagonists. 3. Inoculation of seed potatoes with different fungi. Neth. J. Plant Pathol. 90:117-126.

31. Vanderplank, J. E. 1968. Disease resistance in plants. Academic Press, New York.

32. Van Eeuwijk, F. A. 1995. Multiplicative interaction in generalized linear models. Biometrics 51:1017-1032.

33. Van Eeuwijk, F. A. 1996. Between and beyond additivity and non-additivity: The statistical modelling of genotype by environment interaction in plant breeding. Ph.D. thesis. Wageningen Agricultural University, Wageningen, Netherlands.

34. Van Eijk, J. P., Van Raamsdonk, L. W. D., Eikelboom, W., and Bino, B. J. 1991. Interspecific crosses between Tulipa gesneriana cultivars and wild Tulipa species: A survey. Sex. Plant Reprod. 4:1-5.

35. Van Keulen, H., and Van Aartrijk, J. 1993. Ziektegevoeligheid van cultivars van bloembolgewassen. Milieuplatform Bloembollensektor, Hillegom.

36. Van Raamsdonk, L. W. D., Van Eijk, J. P., and Eikelboom, W. 1995. Crossability analysis in subgenus Tulipa of the genus Tulipa L. Bot. J. Linnaean Soc. 117:147-158.

37. Weinhold, A. R., Dodman, R. L., and Bowman, T. 1972. Influence of exogenous nutrition on virulence of Rhizoctonia solani. Phytopathology 62:278-281.

38. Wilmink, A. 1996. Genetic modification of tulip by means of particle bombardment. Ph.D. thesis. Katholic University of Nijmegen, Nijmegen, Netherlands.

39. Yang, H. A., Zhou, J., Sivasithamparam, K., Tommerup, I. C., Barton, J. E., and O'Brien, P. A. 1994. Genetic variability in pectic enzymes of Rhizoctonia solani isolates causing bare patch disease of cereals. J. Phytopathol. 141:259-266

40. Yitbarek, S. M., Verma, P. R., and Morall, R. A. A. 1987. Anastomosis groups, pathogenicity, and specificity of Rhizoctonia solani isolates from seedling and adult rapeseed/canola plants and soils in Saskatchewan. Can. J. Plant Pathol. 9:6-13.

41. Zadoks, J. C., and Schein, R. D. 1979. Epidemiology and plant disease management Oxford University, Oxford

42. Zadoks, J. C., and Van Leur, J. A. G. 1983 Durable resistance and host-pathogen-environment interaction. Pages 125-139 in: Durable Resistance in Crops. F. Lamebrain, J. M Waller, and N. A. Van der Graaf, eds. Plenum Publishing, New York. 